\title{
Age-Related Changes in the Rate of Oviposition of Three Species of Hippelates (Diptera: Chloropidae) Eye Gnats: Experimental and Mathematical Analysis ${ }^{1}$
}

\author{
M. G. KARANDINOS ${ }^{2}$ AND R. C. AXTELL \\ Department of Entomology, North Carolina State University, Raleigh 27607
}

\section{ABSTRACT}

The mean number of eggs laid per female in cohorts of Hippelates pusio Loew, H. bishoppi Sabrosky, and $H$. pallipes (Loew) were $120.9,76.7$, and 59.8 , respectively. Insects of the 3 species deprived of proteinaceous diet $7 \mathrm{~h}$ after their emergence and given only $10 \%$ sucrose solution laid only $16.7,16.8$, and 15.9 eggs per female, respectively. Shorter adult life spans and lower daily rates of egg laying contributed to the observed reduction.

The daily oviposition rate increased rapidly during the first 5-7 days of cohort's age and declined gradually afterwards. Gamma distribution functions described the data. This common type of oviposition trend was shown to be an artifact of pooling the records from different females having large variance in preovipositional time.
Individual records from 45 pairs of $H$. pusio revealed oviposition occurred in distinct gonotrophic cycles. The mean number of eggs per live female declined exponentially with the physiological age of females. The mean number of gonotrophic cycles per female was 9.93, with a mean gonotrophic cycle length of 3.23 days. An indirect probabilistic method was developed for estimating the duration of the oviposition phase of a gonotrophic cycle. The greater the number of eggs per batch, the longer the oviposition phase, with an asymptote of approximately $11 \mathrm{~h}$.
The rate of increase of any insect species depends on many factors including the age-specific fertility, the age-specific rate of oviposition, and the pattern of female survivorship. The age-related changes in the fertility of 3 species of Hippelates eye gnats have been reported (Karandinos and Axtell 1972). This paper presents our findings on the age-related changes in the rate of oviposition of these species, and the survivorship curve obtained in laboratory experiments.

Changes in the oviposition rate with age of adult insects have been found for many species (Englemann 1970). Most workers have obtained their data from experiments with cohorts of insects, and some (e.g., Dick 1937, Dunn 1923, Johansson 1958, Shapiro 1932) from isolated pairs.

Clearly, data of the latter type reflect physiological and/or structural changes with time in the reproductive system of individual organisms. Data of the former type reflect an additional kind of changes pertaining to a cohort of individuals. In order to distinguish the 2 kinds of changes, experimental results from cohorts and analytical records from isolated pairs of animals are required. Such records are not usually available in the literature.

In the present work, data were collected and analyzed in an effort to evaluate the above 2 kinds of changes in oviposition rate. The rate of oviposition in cohorts of $H$. pusio Loew, H. bishoppi Sabrosky, and $H$. pallipes (Loew) was determined. The survivorship curves of the 3 species were obtained. Data from isolated pairs of $H$. pusio were collected and their contribution to the cohort's oviposition rate of this species was investigated. Simple mathematical

${ }^{1}$ Research supported in part by PHS Training Grant ES 00069 from the National Institutes of Environmental Health Sciences and NSF Science Development Grant GU 1590 for biomathematics. Paper. No. 4117 of the Journal Series of the North Carolina State Univ. Agric. Exp. Stn. We thank Dr. R. D Shenefelt (Univ. of Wisconsin) and Dr. R. Stinner (NCSU) for helpful suggestions in preparation of this paper. Received for publication Oct. 2, 1973 .

2 Present address: Dept. of Entomology, Univ. of Wisconsin, Madison 53706. relations describing the observed egg output of individuals with time were found. These relations can lead to the formulation of plausible hypotheses concerning the underlying physiological and/or structural changes in the reproductive system of this species due to aging.

The average number of eggs oviposited by a female insect is often affected by the adult's diet (Robertson and Sang 1944, Strangways-Dixon 1961, Turner and Hair 1967). We determined the number of eggs laid by the 3 species of Hippelates when they were fed on a nonproteinaceous diet shortly after their eclosion, as compared to the number of eggs laid by females fed on proteinaceous diets throughout their life.

\section{EXPERIMENTS WITH COHORTS}

Methods.-Colonies of Hippelates eye gnats had been established from adults collected in North Carolina 4 yeats prior to the time of this study. Rearing details have been reported elsewhere (Axtell 1964, Karandinos and Axtell 1972).

Pairs of flies were confined in plastic cylindrical containers $(3.6 \mathrm{~cm}$ height and $5.2 \mathrm{~cm}$ diam). Six such units, each containing 75 pairs, were used for each species. Adequate ventilation, water and food (mixture of dried beef blood, honey, strained prunes, and yeast) were provided. The experiments were conducted at $33^{\circ} \mathrm{C}, 55 \% \mathrm{RH}$, and continuous light. The flies had emerged during a $14-\mathrm{h}$ interval prior to the initiation of experiments. The surviving flies were transferred daily to clean containers; the dead were sexed, counted, and discarded. The eggs were counted under a binocular microscope.

Results and analysis.-The survivorship curves for these cohorts are given in Fig. 1 (upper curves). The lower curves for each species in this figure were obtained from identical experiments except that flies had access to water and the standard proteinaceous diet only during the first $7 \mathrm{~h}$ of their adult life and $10 \%$ sucrose solution afterwards. The total egg out- 


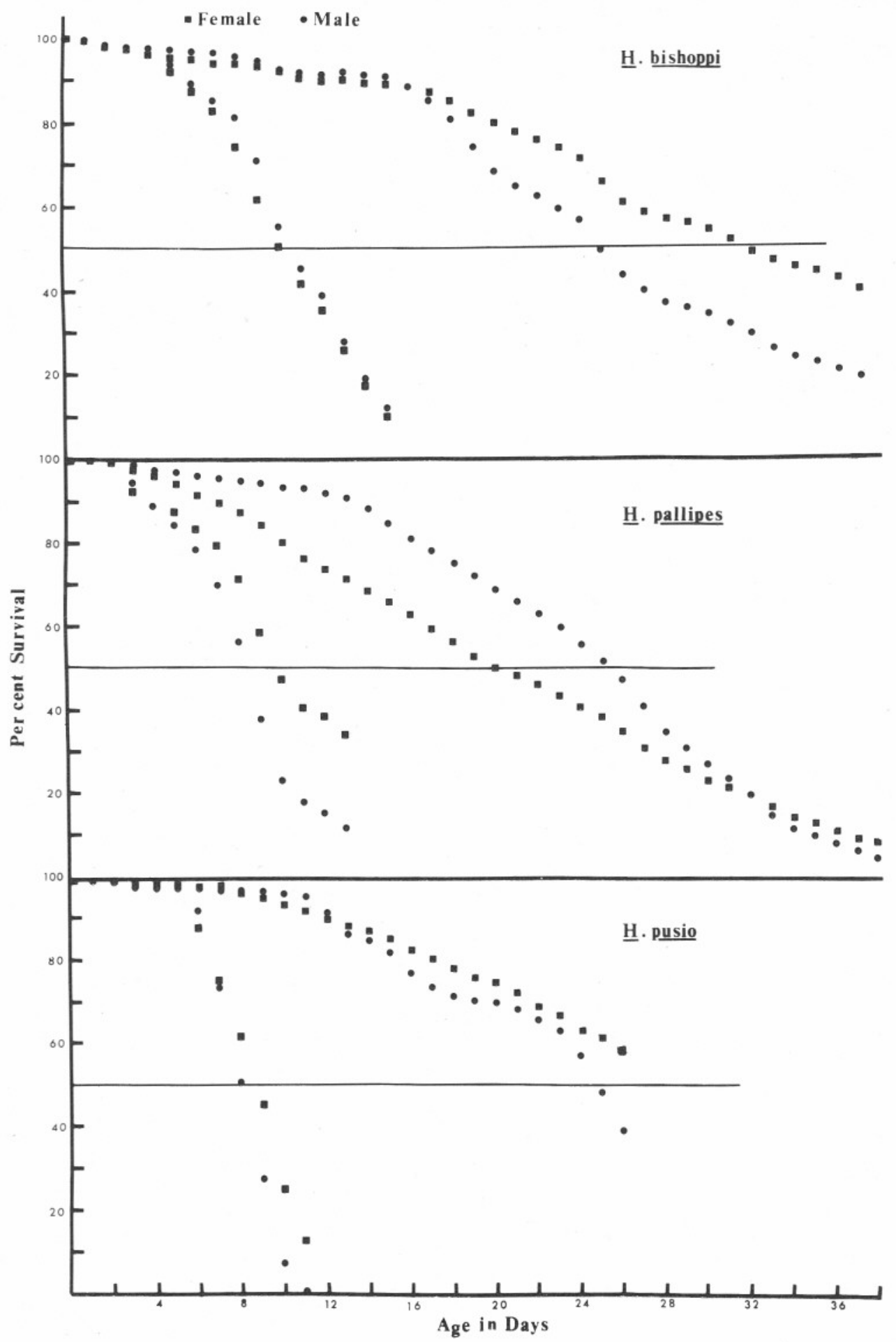

FIG. 1.-Survivorship curves of 3 species of Hippelates under 2 diet conditions. (See text for explanations). 
Table 1.-Effect of 2 diets on mean number of eggs laid per female of 3 species of Hippelates. Six containers with 150 individuals ( $\operatorname{sex}$ ratio $1: 1$ ) in each were used for each diet-species combination.

\begin{tabular}{lrc}
\hline \hline Species & Protein $^{\mathrm{a}}$ & Sucrose $^{\mathrm{b}}$ \\
\hline H. pusio & 120.90 & 16.74 \\
H. bishoppi & 76.68 & 16.89 \\
H. pallipes & 59.84 & 15.98 \\
\hline
\end{tabular}

a Standard diet (see text)

b Standard diet the first $7 \mathrm{~h}$ of adult's life, then $10 \%$ sucrose solution.

put was drastically decreased on the sugar diet (Table 1) due to shorter life span and reduced daily rate of oviposition of the surviving flies.

The daily egg output divided by the number of females at the beginning of the experiment for the 3 species are given in Fig. 2. The daily rate of oviposition increased sharply until about the 6th daydepending on the species-and declined gradually afterwards. This general pattern of ovipsition has been reported for many insect species. We should, however, realize that the "shape" of such a trend can be substantially changed as a result of completely extrinsic and arbitrary procedures such as the length of time unit chosen for collecting the data and/or "smoothing" them. In the present work, we chose a day unit for collecting and presenting the data. This is a meaningful unit, as will become apparent in the next section. No "smoothing" was done. The following matematical function described the trend in the rate of oviposition:

$$
Y_{t}=Y_{T} t^{a-1} e^{-(t / b)} / b^{a} \Gamma(a) \quad \text { for } 0<t<\infty
$$

where $Y_{t}$ is the number of eggs per day per female, $t$ is the age of the cohort, $Y_{T}$ is the observed total number of eggs laid per female, $a$ and $b$ are the parameters to be estimated from the data, and $\Gamma(\mathrm{a})$ is the gamma function of a. Since the second part of this function has the form of the well known gamma distribution (Hogg and Craig 1965), it was relatively easy to estimate the parameters. We solved the system of equations :

$$
\begin{aligned}
& \text { sample mean }=a b \\
& \text { sample variance }=a b^{2}
\end{aligned}
$$

to obtain moment estimates. These were used as starting values in an iterative process to obtain least square estimates. The data for the first 20 days were used. The estimates obtained and the theoretical curves are given in Fig. 2. The mode of gamma distribution is $(\mathrm{a}-1) \mathrm{b}$, which in this case is $6.53,7.34$, and 5.73 days for $H$. pusio, $H$. bishoppi, and $H$. pallipes, respectively, indicated by arrows in Fig. 2. The ranking of magnitudes of these parameters for the 3 species is consistent with the ranking of developmental times of eggs of these species (Karandinos and Axtell 1967).

The gamma distribution has the advantage that existing tables (Pearson 1922) can be used to easily obtain an integral value of the function, i.e., the cumulative expected number of eggs oviposited from time 0 to time $\tau$.
Several components can be thought to contribute to the observed general trend in the rate of oviposition as the age of cohort increases: (a) changes in the reproductive capacity of individual females, (b) variability in the pre-ovipositional time, (c) variability in the length of reproductive life, and (d) interactions among flies in the cohort. The data in the section below elucidate the role of these components.

\section{EXFERIMENTS WITH ISOLATED PAIRS}

Methods.-Forty-five pairs of $H$. pusio were confined as individual pairs in small $(3.65 \mathrm{~cm}$ height and $2.15 \mathrm{~cm}$ diam) cylindrical plastic containers. The mean age of flies was $2 \mathrm{~h}$ at the beginning of the experiment. Standard diet and water were provided. The flies were transferred to clean containers and the eggs were counted twice a day for the first 5 days and once a day afterwards. The observations continued until the last female died.

Results and analysis.-The original records of a sample of 10 representative females during the first 10 days of observation are given in Table 2. Oviposition by individual females occurred in distinct gonotrophic cycles. Detinova (1962) introduced the term "gonotrophic cycle" in studies on reproduction of Diptera. Adams and Mulla (1967) used that term to describe the observed perioidic cycles in oviposition and oogenesis of $H$. collusor. We adopt the same term for $H$. pusio in this paper although the periodicity may not be of truly gonotrophic nature.

The number of eggs deposited by $H$. pusio decreased in successive cycles (Table 2) and the preovipositional time was highly variable (Table 3 ). Thus, the increasing limb of the oviposition curve observed in the cohort experiment was simply an artifact of the situation. No significant correlation coefficient $(r=0.28$ ) was found between physiological age and interval between adjacent cycles; therefore, this variable did not contribute to the declining limb of the curve.

In order to analyze the oviposition phenomenon in terms of gonotrophic cycles (physiological age) rather than in terms of arbitrary time units, it was desirable to reduce the "noise" from the data. In many cases, adjacent to a large batch of eggs was a smaller one. We assumed they belonged to the same cycle which had been interrupted at the time of observation. On the other hand, an egg batch followed by a larger nonadjacent one was accepted as belonging to a distinct cycle. Detinova (1962), referring to mosquitoes, stated that an ovariole that produces a degenerate follicle can produce an egg in the next gonotrophic cycle. Thus, although the overall trend in the number of functional ovarioles is a decreasing one, it is possible occasionally to have a cycle with larger number of eggs than in a previous one.

The next step was to tabulate the number of eggs produced in the $i^{\text {th }}$ cycle for all females under the same column as shown in Table 4 for the 10 representative females. A number of vital statistics (Table 3) was computed from all 45 females. The mean pre- 


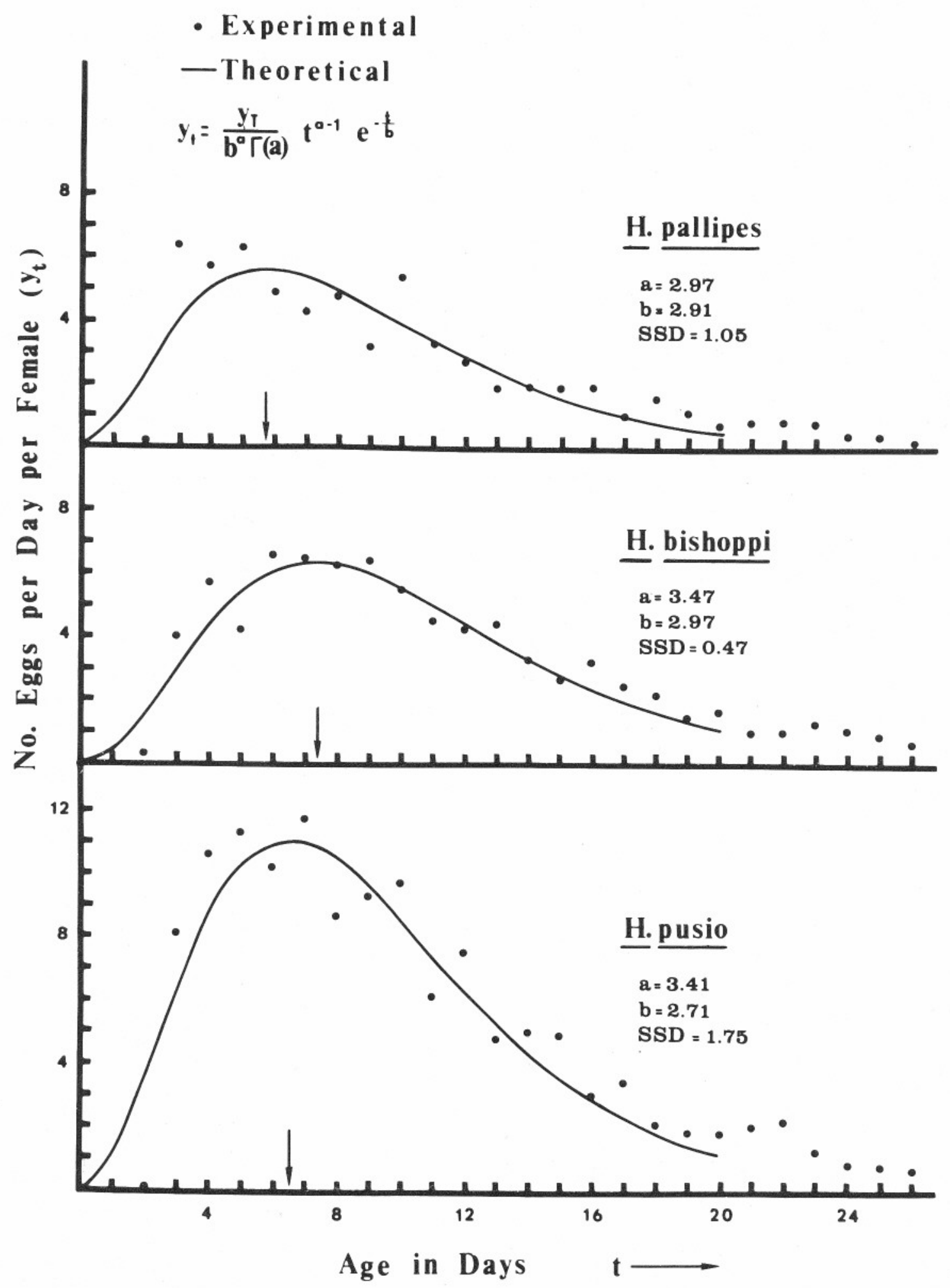

FIG. 2.-Experimental and theoretical oviposition rates in cohorts of 3 species of Hippelates. 
Table 2.-Oviposition records for 10 selected females of $H$. pusio during the first 10 days of their life.

\begin{tabular}{|c|c|c|c|c|c|c|c|c|c|c|c|c|c|c|c|}
\hline \multirow{3}{*}{$\frac{\text { Individual }}{1}$} & \multicolumn{15}{|c|}{ Day } \\
\hline & \multicolumn{2}{|c|}{1} & \multicolumn{2}{|c|}{2} & \multicolumn{2}{|r|}{3} & \multicolumn{2}{|c|}{4} & \multicolumn{2}{|c|}{5} & \multirow{2}{*}{$\begin{array}{c}6 \\
28\end{array}$} & \multirow{2}{*}{$\begin{array}{l}7 \\
0\end{array}$} & \multirow{2}{*}{$\begin{array}{l}8 \\
0\end{array}$} & \multirow{2}{*}{$\frac{9}{25}$} & \multirow{2}{*}{$\begin{array}{r}10 \\
0\end{array}$} \\
\hline & 0 & 0 & 0 & 0 & 0 & 0 & 34 & 0 & 0 & 3 & & & & & \\
\hline 2 & 0 & 0 & 0 & 0 & 0 & 8 & 24 & 0 & 0 & 0 & 26 & 0 & 0 & 1 & 22 \\
\hline 3 & 0 & 0 & 0 & 0 & 0 & 26 & 0 & 10 & 9 & 0 & 0 & 14 & 0 & 0 & 14 \\
\hline 4 & 0 & 0 & 0 & 0 & 0 & 0 & 0 & 0 & 17 & 0 & 0 & 0 & 16 & 0 & 0 \\
\hline 5 & 0 & 0 & 0 & 0 & 0 & 0 & 29 & 0 & 0 & 0 & 0 & 28 & 0 & 21 & 0 \\
\hline 6 & 0 & 0 & 0 & 0 & 0 & 0 & 0 & 13 & 0 & 0 & 0 & 17 & 0 & 0 & 0 \\
\hline 7 & 0 & 0 & 0 & 0 & 0 & 24 & 0 & 0 & 0 & 12 & 5 & 0 & 10 & 0 & 10 \\
\hline 8 & 0 & 0 & 0 & 0 & 0 & 0 & 0 & 0 & 0 & 6 & 13 & 0 & 14 & 0 & 0 \\
\hline 9 & 0 & 0 & 0 & 0 & 0 & 0 & 19 & 0 & 0 & 0 & 17 & 0 & 0 & 0 & 13 \\
\hline 10 & 0 & 0 & 0 & 0 & 0 & 30 & 0 & 0 & 0 & 0 & 24 & 0 & 0 & 16 & 0 \\
\hline
\end{tabular}

ovipositional time (3.74 days) was significantly greater than the mean duration of the other cycles (3.23 days). This phenomenon has also been observed for $H$. collusor by Adams and Mulla (1967b), who attributed it to the development of secondary follicle through stage 2 before completion of development and oviposition of the primary one. They found that the mean time between the egg production peaks was 3.5 days. The correlation coefficients between the variables $\mathrm{X}_{1}, \mathrm{X}_{2} ; \mathrm{X}_{1}, \mathrm{X}_{3}$; and $\mathrm{X}_{2}, \mathrm{X}_{3}$ (Table 3 ) were $0.6365,0.5220$, and 0.8598 , respectively. All were significant at the $1 \%$ level.

The mean number of eggs (Table 5) in the $\mathrm{i}^{\text {th }}$ gonotrophic cycle was computed in 2 ways: the number of eggs per female $\left(Y_{i}\right)$ and the number of eggs per female alive $\left(A_{i}\right)$. We found mathematical models giving $A_{i}$ and $Y_{i}$ in terms of i. First a logarithmic transformation of $A_{i}$ gave data described closely by a straight line (Fig. $3,2_{\mathrm{T}}$ ). Therefore,

$$
\mathrm{A}_{\mathrm{i}}=\mathrm{ce}^{-\lambda^{\mathrm{i}}}
$$

where $\mathrm{i}$ is the physiological age in units of gonotrophic cycles and $\mathrm{c}$ and $\lambda$ are parameters to be estimated from the data. The exponential nature of the decline in $A_{1}$ was further demonstrated by grouping the 45 females with respect to the number of gonotrophic cycles, the total egg production, and preovipositional period. In all these groups the decline was one of exponential nature. In Fig. 3 ( $1 \mathrm{G}$ and $2 \mathrm{G}$ ) the data from one such group of 26 females are given.
This simple "decay" model is very common in many dynamic biological phenomena. It is the solution of a differential equation that describes the well known law that the decrease of some quantity $A_{i}$ per unit of time $\mathrm{i}$ is proportional to $\mathrm{A}_{\mathrm{i}}$.

The least square estimates of the parameters $\mathrm{c}$ and $\lambda$ were:

$$
\hat{\mathrm{c}}=22.045 \text { and } \hat{\lambda}=0.08759
$$

thus

$$
\mathrm{A}_{\mathrm{i}}=22.045 \mathrm{e}^{-0.05789 \mathrm{i}}
$$

This curve is given in Fig. 3 in both the original $\left(1_{\mathrm{T}}\right)$ and the logarithmic $\left(2_{\mathrm{T}}\right)$ form. It follows from (2) that

$$
\frac{\mathrm{A}_{\mathrm{i}+1}}{\mathrm{~A}_{\mathrm{i}}}=0.9174
$$

i.e. the number of eggs in a given cycle is $91.74 \%$ of

\begin{tabular}{|c|c|c|c|}
\hline Statistic & Mean & SE & C.V. \\
\hline Preoviposition time (days) & 3.74 & 0.17 & 30.92 \\
\hline No. eggs/female $\left(X_{1}\right)$ & 134.79 & 7.94 & 39.59 \\
\hline No. gonotrophic cycles $\left(\mathrm{X}_{2}\right)$ & 9.93 & 0.57 & 38. \\
\hline Life span, days $\left(\mathrm{X}_{3}\right)$ & 37.89 & 2.06 & 36.5 \\
\hline Eggs/day & 3.84 & 0.28 & 48.41 \\
\hline Days between gonotrophic cycles & 3.23 & 0.05 & 32.82 \\
\hline
\end{tabular}
the eggs in the preceding one.

Table 3.-Vital statistics of reproduction of H. pusio

\begin{tabular}{|c|c|c|c|c|c|c|c|c|c|c|c|c|c|c|c|c|c|c|}
\hline \multirow[b]{2}{*}{ Individual } & \multicolumn{18}{|c|}{ Gonotrophic cycle } \\
\hline & 1 & 2 & 3 & 4 & 5 & 6 & 7 & 8 & 9 & 10 & 11 & 12 & 13 & 14 & 15 & 16 & 17 & 18 \\
\hline 1 & 34 & 31 & 25 & 23 & 24 & 24 & 15 & 13 & 7 & & & & & & & & & \\
\hline 2 & 32 & 26 & 23 & 18 & 17 & 7 & 11 & 14 & & & & & & & & & & \\
\hline 3 & 26 & 19 & 14 & 14 & 14 & 14 & 13 & 14 & 11 & 5 & 11 & 3 & 8 & 5 & & & & \\
\hline 4 & 17 & 16 & 8 & 9 & 6 & 4 & & & & & & & & $J$ & & & & \\
\hline 5 & 29 & 28 & 21 & 15 & 15 & 15 & 12 & 8 & 6 & 5 & 11 & 6 & 5 & 11 & 4 & 3 & & \\
\hline 6 & 13 & 17 & 14 & 15 & 15 & 9 & 8 & 8 & 8 & 9 & 14 & & & & & & & \\
\hline 7 & 24 & 17 & 10 & 10 & 10 & 9 & 8 & 7 & 4 & 7 & 4 & 5 & 8 & 5 & 4 & 8 & 6 & 4 \\
\hline 8 & 19 & 14 & 11 & 10 & 8 & 7 & 10 & & & & & & & & & & & \\
\hline 9 & 19 & 17 & 13 & 11 & 11 & 10 & 8 & & & & & & & & & & & \\
\hline 10 & 30 & 24 & 16 & 14 & 6 & 12 & 10 & 8 & & & & & & & & & & \\
\hline Total & 243 & 209 & 155 & 139 & 125 & 111 & 95 & 72 & 36 & 26 & 40 & 14 & 21 & 21 & 8 & 11 & 6 & 4 \\
\hline
\end{tabular}
based on data from 45 females.

Table 4.-Oviposition records per gonotrophic cycle of 10 selected females of $H$. pusio during their life span. 
Table 5.-Oviposition of H. pusio in isolated pairs.

\begin{tabular}{|c|c|c|c|c|c|c|c|}
\hline \multirow{2}{*}{$\begin{array}{l}\text { Gon. } \\
\text { cycle }\end{array}$} & \multirow{2}{*}{$\begin{array}{l}\text { No. } \\
\text { females } \\
\text { alive } \\
\mathrm{N}\end{array}$} & \multirow{2}{*}{$\begin{array}{l}\text { Egg } \\
\text { total } \\
\text { E }\end{array}$} & \multirow{2}{*}{$\begin{array}{c}\text { No. eggs } \\
\text { per } \\
\text { female } \\
Y_{i}\end{array}$} & \multirow{2}{*}{$\begin{array}{l}\text { No. eggs } \\
\text { per female } \\
\text { alive } \\
A_{i}\end{array}$} & \multicolumn{3}{|c|}{ Days between cycles } \\
\hline & & & & & Mean & SE & C.V. \\
\hline 1 & 45 & 996 & 22.13 & 22.13 & 3.735 & 0.172 & 30.96 \\
\hline 2 & 45 & 817 & 18.15 & 18.15 & 2.663 & 0.111 & 28.08 \\
\hline 3 & 43 & 724 & 16.09 & 16.84 & 2.895 & 0.133 & 30.28 \\
\hline 4 & 43 & 642 & 14.27 & 14.93 & 2.880 & 0.140 & 33.58 \\
\hline 5 & 40 & 565 & 12.55 & 14.12 & 3.175 & 0.163 & 32.59 \\
\hline 6 & 40 & 506 & 11.24 & 12.65 & 3.725 & 0.289 & 49.02 \\
\hline 7 & 37 & 447 & 9.93 & 12.08 & 3.405 & 0.227 & 40.65 \\
\hline 8 & 32 & 371 & 8.24 & 11.59 & 3.219 & 0.313 & 55.08 \\
\hline 9 & 27 & 253 & 5.62 & 9.37 & 3.231 & 0.279 & 44.04 \\
\hline 10 & 26 & 213 & 4.73 & 8.19 & 3.269 & 0.316 & 49.37 \\
\hline 11 & 22 & 185 & 4.11 & 8.41 & 4.136 & 0.274 & 31.04 \\
\hline 12 & 19 & 138 & 3.07 & 7.26 & 3.450 & 0.426 & 55.21 \\
\hline 13 & 10 & 83 & 1.84 & 8.30 & 3.600 & 0.371 & 32.61 \\
\hline 14 & 8 & 55 & 1.22 & 6.87 & 2.750 & 0.313 & 32.24 \\
\hline 15 & 5 & 34 & 0.75 & 6.80 & 3.750 & 0.854 & 45.55 \\
\hline 16 & 3 & 13 & 0.29 & 4.33 & 4.000 & 1.000 & 35.35 \\
\hline 17 & 1 & 6 & 0.13 & 6.00 & 2.000 & & - \\
\hline 18 & 1 & 4 & 0.09 & 4.00 & 5.000 & - & - \\
\hline
\end{tabular}

A mathematical model for $Y_{i}$ was derived as follows :

Let

$\mathrm{P}_{\mathrm{i}}$ be the probability that a female will oviposit in the $\mathrm{i}^{\text {th }}$ gonotrophic cycle.

$$
\mathrm{i}=1,2,3, \ldots \ldots \text {. }
$$

$\mathrm{X}$ be the number of gonotrophic cycles a female accomplishes before she dies.

$$
\mathrm{X}=0,1,2, \ldots .
$$

$\mathrm{P}_{\mathrm{X}}$ be the probability that a female will accomplish $\mathrm{X}$ gonotrophic cycles before she dies.

It follows from the above definitions that

$$
\mathrm{Y}_{\mathrm{i}}=\mathrm{A}_{\mathrm{i}} \mathrm{P}_{\mathrm{i}}
$$

It is also deduced that the probability of a female to oviposit in the $\mathrm{i}^{\text {th }}$ cycle equals the probability that she will accomplish $\mathrm{X}$ cycles before she dies; $\mathrm{X}$ takes the values $i, i+1, i+2, \ldots \ldots$

$$
P_{i}=\sum_{X=i}^{X} P_{X}
$$

Our data showed that the variable $\mathrm{X}$ had approximately a normal distribution, and the maximum likelihood estimates of the parameters were: mean $=9.93$ and variance $=14.24$.

To be consistent with the acceptance of a continuous distribution for X relation (4) is written

$$
P_{i}=\int_{i}^{\infty} P_{X} d X
$$

To facilitate use of Normal Tables and computation we worked with the completement of (5), i.e.,

$$
\mathrm{P}_{\mathrm{i}}=1-\int_{0}^{i} \mathrm{P}_{\mathrm{X}} \mathrm{dX}
$$

Substituting $A_{i}$ and $P_{i}$ in (3) from (1) and (6) we obtained

$$
Y_{i}=\left(\mathrm{ce}^{-\lambda \mathrm{i}}\right)\left[1-\int_{0}^{i} \mathrm{P}_{\mathrm{X}} \mathrm{dX}\right]
$$

The theoretical $Y_{i}$ 's from (7) and those observed from Table 5 were plotted in Figure $3\left(1_{\mathrm{T}}\right.$ and $2_{\mathrm{T}}$ ) for visual inspection of the goodness of fit.

The actual oviposition of the eggs of a gonotrophic cycle was usually accomplished during the 24 -h interval between observations. In many cases $(28 \%)$, however, the oviposition of the eggs of a gonotrophic cycle was split to 2 adjacent observational periods. The mean number of eggs per gonotrophic cycle, based on 118 such broken cycles, was $14.711 \pm 0.646$ (SE) compared to $11.986 \pm 0.372$ based on 302 nonbroken cycles. The difference of the means was significant at the $1 \%$ level. A logical explanation is that the larger batches of eggs take longer to be oviposited and therefore have a greater chance to be broken by the observation. Such an explanation is supported by the data in Table 6 , in which the larger the batch the greater the proportion of broken phases. Since, however, a large proportion of phases (ca. 60\%) are nonbroken even for the largest batches, we can assume the duration of the oviposition phase is less than $24 \mathrm{~h}$. We developed an indirect method for estimating the duration $\mathrm{d}$ of the oviposition phase utilizing the above data. A basic assumption of the method was that all points of a gonotrophic cycle have equal probability of being "hit" by a "timepoint" of an observation; i.e., the gonotrophic cycles of various individuals are not synchronized but occur randomly. Our data (Table 2) obtained under constant environmental conditions seem to justify this assumption. The disappearance of synchronization under conditions of continous illumination has been demonstrated for Drosophila sp. by Azaryan (1968) and discussed by Beck (1968). The formal derivation of the estimator $\mathrm{d}$ is given in Appendix, and the results in the last 2 columns of Table 6 . We observed that the duration 


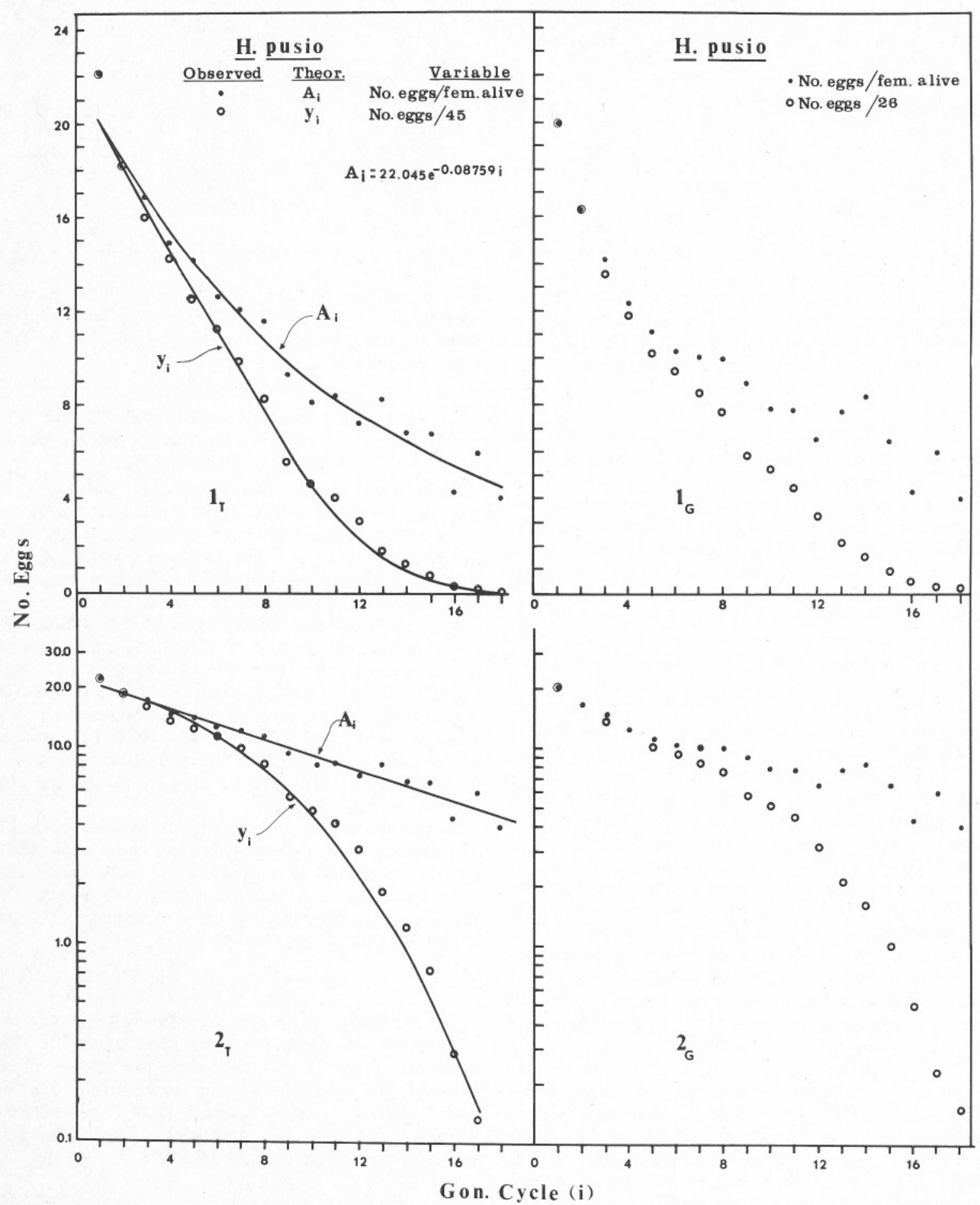

FIg. 3.-Observed (dots and circles) and theoretical (lines) oviposition rates per gonotrophic cycle of $H$. pusio. The same data for all 45 females (left side) are plotted on linear (upper, 1 $1_{T}$ ) and semilogarithmic (lower, $2_{\mathrm{T}}$ ) scales. Data for a subgroup of 26 females (right side) are also plotted on linear (upper, $1_{\mathrm{G}}$ ) and semilogarithmic (lower, $2_{G}$ ) scales. Lines $A_{i}$ obtained from the given exponential function. Lines $Y_{i}$ obtained from function ( 7 ) in text. 
Table 6.-Estimation of time (hours) required by $H$. pusio to complete an oviposition phase of a given size.

\begin{tabular}{|c|c|c|c|c|c|}
\hline $\begin{array}{l}\text { Range of } \\
\text { number eggs } \\
\text { per cycle }\end{array}$ & $\begin{array}{c}\text { Total } \\
\text { number } \\
\text { of cycles } \\
\mathrm{M}\end{array}$ & $\begin{array}{c}\text { Number cycles } \\
\text { with broken } \\
\text { oviposition } \\
\text { phase } \\
\text { m }\end{array}$ & $\begin{array}{c}\begin{array}{c}\text { Proportion } \\
\text { of broken } \\
\text { phases }\end{array} \\
\frac{\mathrm{m}}{\mathrm{M}}=\hat{\mathrm{P}}\end{array}$ & $\begin{array}{l}\text { Estimated } \\
\text { duration of } \\
\text { oviposition } \\
\text { phase in hours } \\
\hat{\mathrm{d}}=24 \hat{\mathrm{P}}\end{array}$ & $\begin{array}{c}\text { Estimated } \\
\text { standard } \\
\text { deviation } \\
\mathbf{S}_{\hat{\mathrm{d}}}\end{array}$ \\
\hline $\begin{array}{c}1-5 \\
6-10 \\
11-15 \\
16-20 \\
21-25 \\
26-30 \\
31-35\end{array}$ & $\begin{array}{r}42 \\
134 \\
124 \\
63 \\
28 \\
22 \\
7\end{array}$ & $\begin{array}{r}7 \\
28 \\
36 \\
24 \\
11 \\
9 \\
3 \\
\end{array}$ & $\begin{array}{l}0.1667 \\
0.2089 \\
0.2903 \\
0.3809 \\
0.3929 \\
0.4091 \\
0.4286\end{array}$ & $\begin{array}{r}4.0008 \\
5.0136 \\
6.9672 \\
9.1416 \\
9.4296 \\
9.8184 \\
10.2864\end{array}$ & $\begin{array}{l}1.38 \\
0.84 \\
0.98 \\
1.47 \\
2.21 \\
2.51 \\
4.49\end{array}$ \\
\hline $31-35$ & 420 & 118 & & & \\
\hline
\end{tabular}

of oviposition phase of a gonotrophic cycle approaches smoothly an upper asymptote of about $11 \mathrm{~h}$, which is probably the maximum duration of ovipositional phase of this diurnal species under natural conditions.

\section{DISCUSSION}

In his classical book on aging, Comfort (1964, p. 242) stated "senescence of the gonad regularly precedes or accompanies senescence of the owner in a number of phyla-so much so that the declining reproductive capacity is a token of senescence almost as valuable as the direct measurement of increased force of mortality." The data on oviposition of eye gnats presented in this paper support the above general statement. The decline in egg production with age has been observed in other species of insects. Putman and Shannon (1934) found that the rate of oviposition in Aedes (Stegomyia) declined with the age of the mothers. A clear-cut fall in fecundity with physiological age has been observed in some species of Anopheles mosquitoes (Detinova and Gillies 1964).

Our data demonstrate also that the type of oviposition curve obtained from cohorts of insects may be completely different from that of the average individual female. A large variance in the preovipositional time of various individuals can produce an increasing limb in a plot of pooled data. For 3 species of Hippelates, the oviposition curves from such data are described by a gamma distribution function. The oviposition rate of an average female, however, declined in a simple exponential fashion with age. A more complex function was found to describe the average oviposition rate when the distribution of life span was taken into consideration.

The oviposition of eggs in distinct gonotrophic cycles is a well known phenomenon for many species of mosquitoes and other insects. For example, in Rhodnius prolixus periods of egg laying are alternated with periods of relative inactivity (Davey 1965 ), and some beetles oviposit their eggs in batches at intervals of 2-3 days (Dick 1937). For H. pusio this interval is 3.23 days. The actual period of egg laying for each gonotrophic cycle of $H$. pusio is $4-10$ $\mathrm{h}$, depending on the size of the batch of eggs. These type of data are not readily obtained by direct observations but may be calculated from periodic counts by the indirect method of estimation. This method may be usefully applied to other insects where direct determination of the duration of ovipositional periods is not practical.

\section{APPENDIX}

An Indirect Method of Estimating the

Duration of the Oviposition Phase Based on Discrete Observations

Definitions and Assumptions.-Let the time required for the completion of a given size (with respect to the number of eggs) oviposition phase of a gonotrophic cycle be a constant and equal to d, and the time between observations be a constant and equal to $h$. Let $h$ be equal or greater than $d$.

It is assumed that the location of the oviposition phase in time is random. This assumption is met as far as ovipositions from different females are concerned, as we already explained. When successive ovipositions of the same female are considered this assumption is approximately met, since the duration of the oviposition phase is relatively short compared to long and highly variable time intervals between successive ovipositions.

Derivation of the Estimator.-It follows from the above that an observation point has equal probability to "hit" any point of a gonotrophic cycle. Thus, the longer the length $\mathrm{d}$ and the shorter the interval $\mathrm{h}$, the greater proportionally the probability $\mathrm{P}$ of an observation to hit and "break" d, i.e.

$$
\mathrm{P}=\frac{\mathrm{d}}{\mathrm{h}} \text { or } \mathrm{d}=\mathrm{Ph}
$$

When a number of females are observed individually in intervals of length $\mathrm{h}$ during their adult life, the parameter $\mathrm{P}$ can be estimated from the number $\mathrm{M}$ of accomplished ovipositions (number of trials in a binomial process) and the number $m$ of "broken" ovipositions (number of successes). The Maximum Likelihood Estimate (MLE) of $\mathrm{P}$ is

$$
\hat{\mathrm{P}}=\frac{\mathrm{m}}{\mathrm{M}}
$$

Since MLE have the invariance property (Freund $1965)$ the MLE of $d$ is

$$
\hat{\mathrm{d}}=\hat{\mathrm{P}} \mathrm{h}=\frac{\mathrm{m}}{\mathrm{M}} \mathrm{h}
$$


With this method, the variance of $d$ can also be obtained

$$
\mathrm{V}(\hat{\mathrm{d}})=\frac{\mathrm{h}^{2}}{\mathrm{M}^{2}} \mathrm{~V}(\mathrm{~m})
$$

but $\mathrm{m}$ being a variable of a binomial distribution has a known variance

and

$$
\mathrm{V}(\mathrm{m})=\mathrm{MP}(1-\mathrm{P})
$$

$$
\hat{\mathrm{V}}(\mathrm{m})=\mathrm{MP}(1-\hat{\mathrm{P}})=\frac{\mathrm{m}(\mathrm{M}-\mathrm{m})}{\mathrm{M}}
$$

Thus (4) becomes

$$
\hat{\mathrm{V}}(\hat{\mathrm{d}})=\frac{\mathrm{h}^{2} \mathrm{~m}(\mathrm{M}-\mathrm{m})}{\mathrm{M}^{3}}
$$

and

$$
\mathrm{S}_{\hat{\mathrm{d}}}=\frac{\mathrm{h}}{\mathrm{M}} \sqrt{\frac{\mathrm{m}(\mathrm{M}-\mathrm{m})}{\mathrm{M}}}
$$

Equations (3) and (8) were used to compute the last 2 columns in Table 6 .

\section{REFERENCES CITED}

Adams, T. S., and M. S. Mulla. 1967. The reproductive biology of Hippelates collusor (Diptera: Chloropidae). II Gametogenesis. Ann. Entomol. Soc. Am. $60: 1177-82$.

Axtell, R. C. 1964 . Laboratory rearing of Hippelates pusio and $H$. bishoppi (Diptera: Chloropidae). J. Elisha Mitchell Scient. Soc. 80: 225.

Azaryan, A. G. 1968. The diurnal rhythm of the emergence and oviposition of Drosophila transversa F11. and $D$. phalerata Mg. (Diptera: Drosophilidae) under different photoperiodic conditions. Entomol. Rev., Wash. 47: 494-6.

Beck, S. D. 1968. Insect photoperiodism. Academic Press, New York. 288 pp.

Comfort, A. 1964. Aging. The biology of senescence. Rinehart and Winston, New York. 365 pp.

Davey, K. G. 1965. Copulation and egg-production in Rhodnius prolixus: the role of the spermathecae. J. Exp. Biol. 42: 373-8.

Detinova, T. S. 1962. Age-grouping methods in diptera of medical importance. World Health Organization, (Geneva), Monograph Series, No. 47.
Detinova, T. S., and M. T. Gillies. 1964. Observations on the determination of the age composition and epidemiological importance of populations of Anopheles gambiae Giles and Anopheles funestus Giles in Tanganyika. Bull. World Health Org. 30: 23-8.

Dick, J. 1937. Oviposition in certain Coleoptera. Ann. Appl. Biol. 24: 762-96.

Dunn, L. H. 1923. Observations on the oviposition of the house fly Musca domestica, L., in Panama. Bull. Entomol. Res. 13: 301-5.

Engelmann, F. 1970. The physiology of insect reproduction. Pergamon Press, New York. 307 pp.

Hogg, R. V., and A. T. Craig. 1965. Introduction to mathematical statistics. MacMillan Co., New York. 383 pp.

Johansson, A. S. 1958. Relation of nutrition to endocrine-reproductive functions in the milkweed bug Oncopeltus fasciatus (Dalles) (Heteroptera: Lygaeidae). Nytt Mag. Zool. 7 : 1-132.

Karandinos, M. G., and R. C. Axtell. 1967. Temperature effects on the immature stages of Hippelates pusio, H. bishoppi, and H. pallipes (Diptera: Chloropidae). Ann. Entomol. Soc. Am. 60: 1055-62.

Karandinos, M. G., and R. C. Axtell. 1972. Age-related changes in the fertility of Hippelates pusio, $H$. bishoppi, and $H$. pallipes (Diptera: Chloripidae). Ibid., 65: 1092-9.

Pearson, K. 1922. Tables of the incomplete gamma function. Cambridge University Press, Cambridge, Mass.

Putnam, P., and R. C. Shannon. 1934. The biology of Stegomyia under laboratory conditions. Proc. Entomol. Soc. Wash. 36: 217-42.

Robertson, F. W., and J. H. Sang. 1944. The ecological determinants of population growth in a Drosophila culture. I. Fecundity of adult flies. Proc. R. Entomol. Soc. Lond. (B) 132 : 258-77.

Shapiro, H. 1932. The rate of oviposition in the fruit fly Drosophila. Biol. Bull. Mar. Biol. Lab., Woods Hole. 63: 456-71.

Strangeways-Dixon, J. 1961. The relationship between nutrition, hormones and reproduction in the blowfly, Calliphora erythrocephala (Meig.). I. Selective feeding in relation to the reproductive cycle, the corpus allatum volume and fertilization. J. Exp. Biol. 38: 225-35.

Turner, E. C., Jr., and J. A. Hair. 1967. Effect of diet on longevity and fecundity of laboratory-reared face flies. J. Econ. Entomol. 60: 857-9.

\section{Reprinted from the}

Annals of the Entomological Society of America 